\title{
The Role of Psychological Factors in Older Adults' Readiness to Use eHealth Technology: Cross-Sectional Questionnaire Study
}

\author{
Lenka Knapova $^{1,2,3^{*}}$, MA; Adam Klocek ${ }^{1,4^{*}}$, MA; Steriani Elavsky ${ }^{1,2,3 *}$, PhD \\ ${ }_{1}^{1}$ Institute for Research on Children, Youth and Family, Masaryk University, Brno, Czech Republic \\ ${ }^{2}$ Faculty of Informatics, Masaryk University, Brno, Czech Republic \\ ${ }^{3}$ Faculty of Education, University of Ostrava, Ostrava, Czech Republic \\ ${ }^{4}$ Faculty of Social Studies, Masaryk University, Brno, Czech Republic \\ *all authors contributed equally
}

\section{Corresponding Author:}

Lenka Knapova, MA

Institute for Research on Children, Youth and Family

Masaryk University

Joštova 218/10

Brno, 60200

Czech Republic

Phone: 420549498272

Email: knapova@mail.muni.cz

\begin{abstract}
Background: Information and communication technology (ICT) use among older adults has been on the rise in recent years. However, the predictors and mechanisms behind older adults' acceptance and use of ICT are not clear.

Objective: This study aimed to systematically describe ICT usage among Czech older adults and to evaluate the factors influencing their ICT use and readiness to use digital technology to promote health (eHealth readiness). The primary focus was on psychological factors and the role of persons close to older adults.

Methods: The research utilized cross-sectional survey data from a quota-based sample of Czech older adults ( $>50$ years) and persons close to them further referred to as close persons $(\mathrm{N}=250$ dyads). A structural equation modeling framework was used to evaluate relationships between psychological factors, ICT use, and eHealth readiness.

Results: Czech older adults' use of ICT is low with the exception of cell phone usage (cell phone usage by $173 / 250,69.2 \%$; other devices used by 50/250, $20.0 \%$ of older adults or less). Apart from age $(\beta=-.21 ; P<.001)$, eHealth readiness was predicted by ICT use $(\beta=.65 ; P<.001)$. eHealth readiness was also indirectly affected by the need for cognitive closure (NFCC): individuals with a high need for closure perceived more barriers to ICT $(\beta=.23 ; P=.01)$ and more reported barriers were linked to lower ICT usage $(\beta=-.21 ; P=.001)$. The expected positive relationships between eHealth readiness of persons close to older adults and ICT use and eHealth readiness of older adults were not significant, but the total effect of eHealth readiness of persons close to older adults on eHealth readiness of older adults was positive and significant $(\beta=.18 ; P=.01)$, indicating some level of influence of persons close to them on older adults' attitudes and behaviors.

Conclusions: This study provided the first systematic examination of Czech older adults' ICT usage and eHealth readiness. Novel predictors (NFCC and close persons' variables) were evaluated and yielded actionable results. More research is needed to clarify the role of persons close to older adults.
\end{abstract}

(J Med Internet Res 2020;22(5):e14670) doi: $\underline{10.2196 / 14670}$

\section{KEYWORDS}

eHealth; information technology; need for cognitive closure; elderly 


\section{Introduction}

\section{Background}

Older adults ( $>65$ years) are the fastest-growing segment of the population, estimated to account for more than $25 \%$ of the total population by 2050 and outnumbering the youngest segment of children under the age of 15 years by 2045 [1,2]. In sharp contrast with the youngsters, older adults are usually portrayed as uninterested in the ever-evolving technological advancements, and thus, lacking familiarity with information and communication technologies (ICTs). However, recent data indicate a sharp increase in technology use among older adults globally, and the Czech Republic has been no exception to this trend. Whereas in 2012, 79.4\%, 56.2\%, and $17.3 \%$ of Czech adults aged 45 to 54 years, 55 to 64 years, and older than 65 years, respectively, used a computer, these numbers have increased to $88.8 \%, 73.3 \%$, and $32.8 \%$ for the respective age groups in 2017 [3]. A similar increase can be seen in the United States, where the percentage of smartphone users older than 65 years rose from 18\% in 2013 to $42 \%$ in 2017 [4]. Data refined by age and economic activity further support the trend of seniors as the fastest-growing segment of ICT users. The subgroup with the largest increase in the percentage of computer users among Czechs are pensioners, particularly the retired, with only $20.9 \%$ of computer users in 2012 compared with $36.1 \%$ in 2017 [3].

Considering the position of the Czech Republic within the European Union (EU), rates of ICT usage are slightly below the average for member countries of the EU. For instance, the percentage of households connected to the internet in the Czech Republic is $81.7 \%$ as compared with the EU average of $85.4 \%$. The disparities are much more evident in the older segment of the population and for new technological developments such as smartphones and mobile internet. Only $13.1 \%$ of Czech adults aged between 55 and 74 years use mobile phones to connect to the internet, which stands in sharp contrast to the average of $34.2 \%$ for EU member countries. Within the EU, the Netherlands, Denmark, and Luxembourg rank the highest in terms of older adults using mobile internet, with $61.8 \%, 61.4 \%$, and $61.1 \%$, respectively. Curiously, the Czech Republic lags behind even when compared with similar countries (by gross domestic product per capita) such as Hungary, Croatia, and Slovakia with $25.2 \%, 24.2 \%$, and $18.6 \%$ of older mobile internet users, respectively [3]. The lower adoption rates of new ICT technologies (eg, mobile internet) among Czech older adults beg the question of how ready Czech older adults are for the deployment of novel ICT approaches in the field of health and medical services, a notion that has been supported by institutions such as the US Department of Health and Human Services or the European Commission and is incorporated within the EU's strategic goals (eg, Europe 2020 strategy) [5]. If left to persist or widen, the digital divide could exacerbate isolation of older adults and may further disadvantage older adults when seeking services that are rapidly being transformed into the digital domain (eg, mobile banking and Web-based reservation systems) or prevent them from adopting newer technologies (eg, assistive technologies) [6,7].

\section{Information and Communication Technology for Health}

The use of ICT has been argued to have the potential to positively influence older adults' well-being, decrease loneliness, and increase social support and integration into society [8-10]. This could be especially true with new emerging internet-connected or mobile technologies aimed specifically at improving health and health-related behaviors. Specifically, the term electronic health (eHealth) is used to describe healthy behavior promoting interventions and devices which make use of the internet (eg, computers, personal digital assistants, cell phones, smartphones). Mobile health (mHealth) denotes the use of mobile handheld devices in support of medical and public health practice [11]. The use of technologies such as smartphones, smartphone-based apps, and integrated or connected sensors provides new ways to monitor and improve one's health, healthy lifestyle, and overall well-being. To the point, recent studies support the effectiveness of such mHealth or eHealth interventions for improving health-related behaviors, for example, increased physical activity, sleep, or reduced sedentary behavior [12,13]. For example, Muellman et al [12] conducted a systematic review and found that eHealth interventions promoting physical activity delivered through computer or handheld devices led to increased levels of physical activity in adults aged 55 years and older. Similarly, in a recent review, Elavsky et al [13] concluded that there is evidence supporting the effectiveness of mHealth interventions (defined as treatment programs delivered at least partially by a mobile phone, a smartphone, or a tablet) for increasing physical activity and reducing sedentary behavior in adults aged 50 years and older.

Nevertheless, a vital premise for the effectiveness of eHealth interventions is the initial acceptance of the intervention or program as well as adherence to it over time. Uptake of health-promoting technologies is very low even in carefully conducted research conditions [14], and the continued use of the eHealth technology significantly decreases over time [15]. One factor that can contribute both to the low adherence rates observed in existing interventions as well as the slow uptake of eHealth technologies may be low eHealth readiness. Evaluating how prepared individuals are to adopt eHealth technology or intervention might be exceptionally beneficial when studying older adults whose current adoption and usage of eHealth technologies might be low.

\section{Factors Influencing Information and Communication Technology Acceptance}

From a socio-ecological perspective, ICT acceptance among older adults could be best explained by the interaction of factors at multiple levels. At the individual level, ICT use and adoption of new technological developments has been consistently associated with sociodemographic characteristics including age [16-19], education [17-20], income or socioeconomic status $[18,21]$, and marital status [17,18,20]. Vroman et al [17] summarize that nonusers tend to be 75 years or older, have a disability or a chronic health problem, live alone, be single or widowed, and have a lower level of education than ICT users. 
Among psychological characteristics, explanations of technology use focus on individual differences in motivations to use technology (eg, technology acceptance model and its variations or hedonic motivation) [22,23], attitudinal factors (eg, perceived ease or usefulness) [24], self-efficacy toward the system [25,26], or anxiety toward the system [26]. In addition, better cognitive abilities, including memory, learning, and concentration, have been linked to higher technology usage [18,27-29]. Dispositional personality characteristics have been acknowledged as potential drivers of ICT adoption and use among older adults as well $[17,18]$. However, few studies have been conducted so far. One recent study evaluated 17 individual difference predictors of ICT use, indexed with a checklist of 10 different ICTs, including ICTs for health [30]. Need for cognition, defined as an individual's tendency to engage in and enjoy activities that require thinking [31], perceived mastery, and optimism, was found to positively predict ICT use, whereas cynical hostility emerged as a negative predictor [30]. Need for cognition also positively influenced the perceived benefits of ICT use and negatively influenced perceived barriers of ICT use. However, this study was exploratory and included a large number of hypotheses evaluated on one sample without performing any correction for multiple comparisons. Another personality trait which has not been widely studied in the context of ICT use and adoption but might have important implications is the need for cognitive closure (NFCC). NFCC is defined as a desire for a definite answer and an aversion toward ambiguity [32]. Interestingly, NFCC represents both a dimension of stable individual differences and a situationally evocable state [33]. Individuals high in dispositional NFCC feel a desire to quickly reach firm decisions; they are reluctant to have their decisions and views challenged, and they are resistant to information inconsistent with their views [33]. High NFCC individuals were found to be reluctant to change [34] and to be less willing to use innovative technology [35]. Individuals high in NFCC could thus exhibit more negative attitudes toward ICT, including new and innovative technology for improving health, be less prepared to use it, and show lower adoption levels.

Going beyond individual characteristics, other factors in older adults' environments that have been found to affect technology usage of older adults include accessibility, financial support, hardware/software capacity and compatibility, and importantly also support, training, and assistance from others [18,36,37]. Vroman et al [17] add that older adults might be introduced to using ICT for its utility through natural exchanges that occur between family and friends (eg, by receiving hyperlinks via email to view family photos, products, or holiday destinations) and further use ICT as a utility (to search for health-related information, product, and services) and possibly also connect with a virtual community outside one's geographical location. Indeed, previous studies have found that the involvement of family members, especially older adults' children, positively influences ICT adoption [38]. More than 25\% of Czech older adults reported that it was their children, grandchildren, or friends who brought them to use the internet [39]. In a similar vein, Vroman et al [17] found that older adults who live alone, are potentially isolated, and lack a social network are the least likely to use ICT.

\section{This Research}

The objective of this study was to examine ICT use and eHealth readiness of Czech older adults and to evaluate the influence of psychological factors on older adults' readiness to use eHealth technology, while considering the role of older adults' close persons (eg, children and friends). It was hypothesized that older adults with a high NFCC would perceive more barriers to using ICT, use it less, and exhibit lower eHealth readiness. It was also hypothesized that close persons' eHealth readiness would be positively related to older adults' ICT use and eHealth readiness. Finally, as ICT use has been consistently demonstrated to decline with age and age has been shown to be an important predictor of ICT-related attitudes and behavior, the explanatory models tested considered the effect of age when evaluating the associations among NFCC, perceived barriers, current ICT use, and eHealth readiness.

\section{Methods}

\section{Sample and Data Collection}

The study was approved by the University Ethical Committee. A total of 250 Czech older adults and the persons close to them (close persons, $\mathrm{N}=250$ dyads) participated in this research. The data were collected between September and November 2017. Participants were recruited and surveyed through a professional marketing and social research agency using stratified quota sampling. The quotas were set based on most recent census data (Czech Statistical Office) to correspond with the underlying population of adults aged 50 years and older based on region (representation of all 14 regions within the Czech republic with a quota based on resident population within each region), gender, age (50-59 years, 60-69 years, 70 years and older), education, and city size (categorized by number of inhabitants). The resulting primary sample of older adults is thus representative of the overall Czech population of adults of 50 years and older in terms of distribution by age, gender, education, region, and city size. Professional interviewers located in various regions were given quota breakdowns and conducted in-person questionnaires with corresponding participants until the quota was met. Each older respondent from the primary sample identified a close person (such as an adult child, a partner, or a friend) who at least occasionally helps them with day-to-day activities (eg, shopping, doctor's visits, household chores, or running errands) with whom they are in contact at least once a week. All close persons were subsequently interviewed either in person or by telephone. The data from the primary sample of older adults were collected through standardized, structured face-to-face interviews (approximately $45 \mathrm{~min}$ in length) in the households of respondents with the help of a tablet and a questionnaire software. The data were collected at one time point and are cross-sectional.

\section{Measures}

\section{Demographics}

Basic demographic information was collected (ie, age, gender, education, income, residence). 


\section{Information and Communication Technology Use}

Participants provided information about the following devices: computer, laptop, cell phone, smartphone, and tablet. Participants were first asked to indicate the devices they own and use and subsequently report further details such as the daily usage time (hours/day) and length of use. This information was aggregated to form two measures of ICT use: number of devices used and total usage time. The number of devices used was calculated as a sum of all the devices participants reported to use (not own). The total usage time of the ICT devices per day was calculated as the sum of usage times per day provided for the specific devices. When a participant did not report usage of a device (and thus was not asked about the details of its use), the usage time was coded as 0 . Responses for total reported usage time exceeding 24 hours per day ( 3 older adults, 12 close persons) were recoded to a maximum value of 16 hours per day to account for typical sleep duration and basic needs.

In addition, the use of the internet as a specific ICT-related technology was assessed. Participants were asked if they use the internet. Internet users were asked for further information about their internet use, such as the daily usage time (hours/day), length of use, and frequency of use. For nonusers of the internet, the usage time was coded as 0 .

\section{Perceived Barriers to Information and Communication Technology Use}

Participants chose from the following list of barriers generated from previous studies on the topic: Not enough knowledge; Technologies evolve too fast; I have trouble with vision and psychomotorics; I am afraid of making a mistake; I do not have enough support; Too expensive, I cannot afford it; I don't care about internet; Something else. Participants could indicate multiple barriers with the total number of perceived barriers ranging from 0 to 7 .

\section{Electronic Health Readiness}

Both older adults and their close persons completed the eHealth Readiness scale by Bhalla et al [40]. The scale was translated to Czech using the method of double-back translation, with emphasis on systematic equivalence [41]. Inconsistencies in item wording were resolved by group discussion of study authors, which included senior researchers on the topic and bilingual speakers. The items were scored on a 6-point scale ranging from 1 (completely disagree) to 6 (completely agree). The total score was calculated as the sum of all the items. Bhalla et al [40] reported a Cronbach alpha of .81 and .83 for validation samples. Internal consistency in this research was higher: Cronbach alpha was .91 and .87 for the older adults and their close persons, respectively.

\section{Need for Cognitive Closure}

NFCC was measured with the Czech version of the 15-item NFCC Scale [42,43]. The items were scored on a 5-point scale ranging from 1 (completely disagree) to 5 (completelyagree).
The total score was calculated as the arithmetical mean of all the items. Širuček et al [43] reported a Cronbach alpha of .84. The Cronbach alpha in this research was .87 .

\section{Data Analysis}

Statistical analyses were performed using R (R Foundation for Statistical Computing), version 3.4.2 [44], packages psych (version 1.8.3.3), lavaan (version 0.5-23.1097), semPlot (version 1.1), and semTools (version 0.4-14).

The proposed relationships were tested using structural equation modeling (SEM). The structural model was estimated using the maximum likelihood with robust SEs test statistics estimator. The model fit was evaluated using standard measures of model fit: the standardized root mean square residual (SRMR), which should be less than or approximately $0.08[45,46]$; the root mean square error of approximation (RMSEA), with values below 0.05 indicating a close fit and values below 0.08 being less indicative of a good fit $[47,48]$; the comparative fit index (CFI), which should be higher than 0.90 [49]; and the Tucker-Lewis index (TLI) with recommended values greater than 0.90 [50] or 0.95 [46].

\section{Model Testing}

First, we defined three latent variables. The latent variable of ICT use was specified as the combination of three manifest variables: number of used devices, total usage time of the devices, and internet usage time. The measurement model for eHealth readiness was a simple 1-factor model where all items were loaded on a single latent variable. eHealth readiness item 2 was excluded from the scale in both samples as it exhibited high residual correlations with other variables and worsened the overall fit of both the measurement model and the resulting structural model. Moreover, upon closer examination, the item (I feel that my previous experience with online technologies is important to my success with using a lifestyle intervention) intertwines previous experience with opinions about its importance, and the item wording makes it difficult to decide if an individual who has previous experience with online technologies but does not think this experience is important to one's success should be labeled as more or less ready to use eHealth technology. For NFCC, a 1-factor model was defined where all NFCC items loaded on a single latent variable and error correlations between items from the same facet were allowed to account for their common facet source (ie, residual correlations were allowed for triads of items 1-3, 4-6, 7-9, 10-12, and 13-15).

On the basis of research questions and the hypothesized relationships, the structural model portrayed in Figure 1 was tested. With respect to the association between older adults' and close persons' eHealth readiness, the residual covariance between the items from the eHealth readiness scale (specifically item 1) was allowed based on residual correlation matrices, modification suggestions, as well as to account for the dyadic nature of the data and possible shared environment. 
Figure 1. A simplified version of the tested model with path estimates. Ellipses indicate latent variables; rectangles indicate manifest variables; full colored arrows indicate significant relationships (green: positive; red: negative) whereas dashed arrows indicate nonsignificant relationships. eHealth: electronic health; ICT: information and communication technology; NFCC: need for cognitive closure.

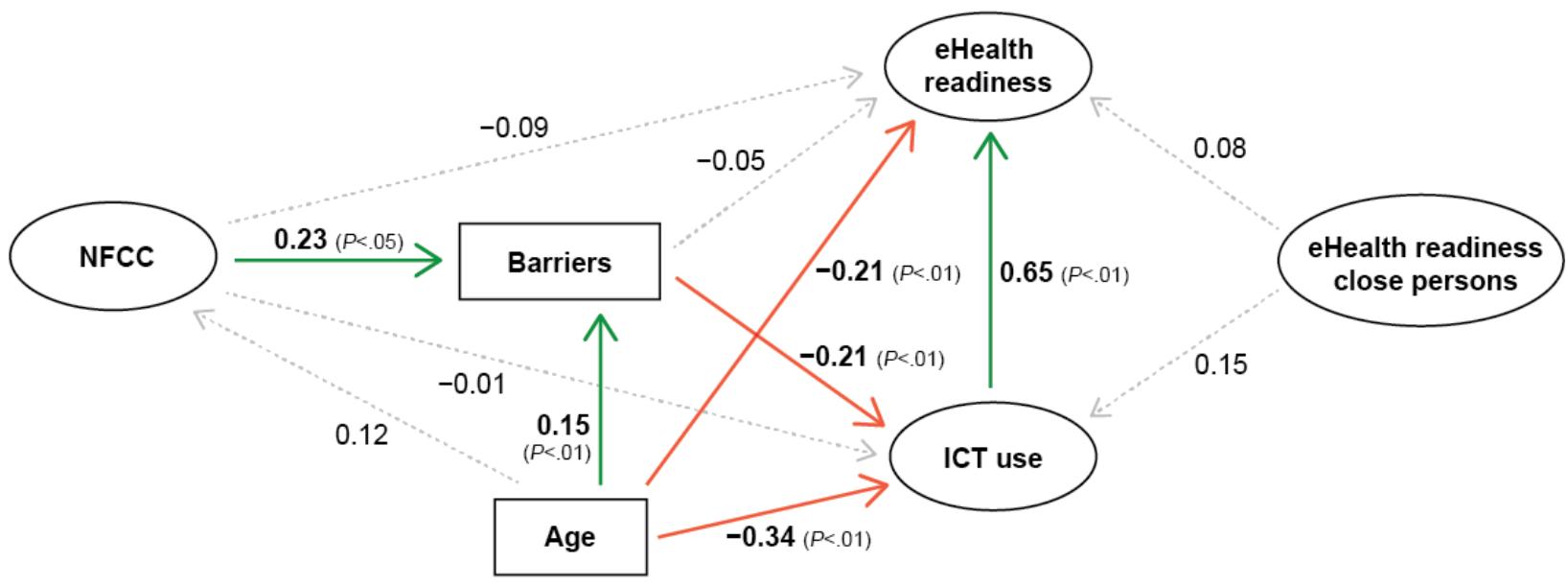

\section{Results}

\section{Sample Characteristics}

The mean age in the older adult sample was 66.14 (SD 9.47) years; $55.2 \%$ (138/250) were women. The majority of the older adults were retired $(188 / 250,75.2 \%)$ and completed high school education $(171 / 250,68.4 \%)$. In the sample of close persons, the mean age was 46.30 (SD 13.51) years; $70.4 \%$ (176/250) were women. Regarding the relationship toward the older adult, $54.8 \%$ (137/250) of close persons were children, $18.0 \%$ (45/250) were other relatives, and $15.2 \%$ (38/250) were partners, the rest accounting for friends, acquaintances, or professional caretakers. Detailed demographic characteristics of both samples can be found in Table 1.

The most widely used device among older adults was the cell phone, with $69.2 \%$ (173/250) of older adults using it on a daily basis. All the other devices were used by less than a fourth of the participants. Details on the mean daily usage (hours/day) of the ICT devices and internet among daily users as well as the total usage time and the total number of devices among all older adults can be found in Table 2. The table also provides details on the number of perceived barriers, NFCC, and eHealth readiness (for the older adults and their close persons as well).

Differences based on gender were examined and are portrayed in Table 2. In total, men used more ICT devices than women, and this difference was significant $\left(\mathrm{t}_{248}=2.12\right.$ [2-talied $t$ test]; $P=.04$; Cohen $d=0.27$ ). No other differences based on gender were significant.
As for the aggregated ICT usage variables, there were significant differences based on education in the total usage time $\left(F_{3,246}=3.23 ; P=.02\right)$, the number of used devices $\left(F_{3,246}=5.40\right.$; $P=.001)$, as well as the number of perceived barriers $\left(F_{3,246}=3.72 ; \quad P=.01\right)$. For usage time, college-educated participants reported higher time than participants with primary education, but the difference was not significant (mean difference $2.44 ; P=.05)$. Participants with primary education used fewer devices than participants with a high-school diploma (mean difference $0.43 ; P=.008$ ) and to a lesser degree than participants with college education (mean difference 0.56; $P=.005$ ). Regarding the number of perceived barriers, the only significant group difference was between participants with primary education who perceived more barriers than college-educated participants (mean difference $0.87 ; P=.02$ ). The most commonly perceived barriers by the older adults related to technologies evolving too fast (indicated by $96 / 250$, $38.4 \%$ of older adults), fear of making a mistake (74/250, $29.6 \%$ ), not being interested in internet technology (55/250, $22.0 \%$ ), technologies being too expensive $(48 / 250,19.2 \%)$, and not having enough knowledge (47/250, 18.8\%).

When comparing older adults with their close persons, close persons used on average more ICT devices (mean 2.03, SD $0.91 ; \mathrm{t}_{249}=-11.91 ; P<.001$; Cohen $\left.d=0.958\right)$, used them for more hours per day (mean 5.32, SD 4.32; $\mathrm{t}_{249}=-10.49 ; P<.001$; Cohen $d=0.76$ ), and perceived fewer barriers to using ICT technology (mean 0.62, SD 0.95; $\mathrm{t}_{249}=9.73 ; P<.001$; Cohen $d=0.79$ ). Nevertheless, the sample of close persons was also significantly younger than the primary sample of older adults $\left(\mathrm{t}_{249}=22.55\right.$; $P<.001$; Cohen $d=1.70$ ). 
Table 1. Demographic characteristics of older adults and their close persons.

\begin{tabular}{|c|c|c|}
\hline Characteristic & Older adults & Close persons \\
\hline \multicolumn{3}{|l|}{ Age (years) } \\
\hline Mean (SD) & $66.14(9.47)$ & $46.30(13.51)$ \\
\hline Range & $50-93$ & $21-90$ \\
\hline \multicolumn{3}{|l|}{ Gender, n (\%) } \\
\hline Females & $138(55.2)$ & $176(70.4)$ \\
\hline Males & $112(44.8)$ & $74(29.6)$ \\
\hline \multicolumn{3}{|l|}{ Education, $\mathbf{n}(\%)$} \\
\hline Elementary & $55(22.0)$ & $10(4.0)$ \\
\hline Secondary school (no diploma) & $101(40.4)$ & $93(37.2)$ \\
\hline Secondary school (diploma) & $70(28.0)$ & $108(43.2)$ \\
\hline University & $24(9.6)$ & $39(15.6)$ \\
\hline \multicolumn{3}{|l|}{ Marital status, n (\%) } \\
\hline Married & $88(35.2)$ & $133(53.2)$ \\
\hline Divorced & $60(24.0)$ & $47(18.8)$ \\
\hline Widowed & 89 (35.6) & $9(3.6)$ \\
\hline Single & $7(2.8)$ & $44(17.6)$ \\
\hline Living with a partner & $6(2.4)$ & $17(6.8)$ \\
\hline \multicolumn{3}{|l|}{ Occupation, n (\%) } \\
\hline Employed & $51(20.4)$ & $172(68.8)$ \\
\hline Retired & $188(75.2)$ & $44(17.6)$ \\
\hline Unemployed & $11(4.4)$ & $28(11.2)$ \\
\hline Students & $\mathrm{N} / \mathrm{A}^{\mathrm{a}}$ & $6(2.4)$ \\
\hline
\end{tabular}

${ }^{\mathrm{a}} \mathrm{N} / \mathrm{A}$ : not applicable. 
Table 2. Descriptive characteristics for the information and communication technology use variables, electronic health readiness, and need for cognitive closure.

\begin{tabular}{|c|c|c|c|c|c|c|c|}
\hline \multirow[t]{2}{*}{ Characteristic } & \multirow{2}{*}{$\begin{array}{l}\text { Proportion of daily users } \\
(\mathrm{N}=250), \mathrm{n}(\%)\end{array}$} & \multicolumn{2}{|l|}{ Entire sample } & \multicolumn{2}{|l|}{ Females } & \multicolumn{2}{|l|}{ Males } \\
\hline & & Mean (SD) & Range & Mean (SD) & Range & Mean (SD) & Range \\
\hline Cell phone usage (hours/day) & $173(69.2)$ & $1.89(3.31)$ & $0.1-24.0$ & $2.21(4.22)$ & $0.1-24.0$ & $1.54(1.82)$ & $0.1-10.0$ \\
\hline Smartphone usage (hours/day) & $19(7.6)$ & $2.05(1.92)$ & $0.5-8.0$ & $1.95(1.61)$ & $0.5-6.0$ & $2.17(2.32)$ & $0.5-8.0$ \\
\hline $\begin{array}{l}\text { Personal computer usage } \\
\text { (hours/day) }\end{array}$ & $50(20.0)$ & $3.16(2.52)$ & $1.0-10.0$ & $3.00(2.49)$ & $1.0-8.0$ & $3.29(2.60)$ & $1.0-10.0$ \\
\hline Laptop usage (hours/day) & $39(15.6)$ & $2.64(1.70)$ & $0.1-7.0$ & $2.49(1.55)$ & $0.1-6.0$ & $2.81(1.89)$ & $0.5-7.0$ \\
\hline Tablet usage (hours/day) & $7(2.8)$ & $1.71(0.76)$ & $1.0-3.0$ & $1.33(0.58)$ & $1.0-2.0$ & $2.00(0.82)$ & $1.0-3.0$ \\
\hline Internet usage (hours/day) & $99(39.6)$ & $2.24(1.98)$ & $0.1-10.0$ & $2.23(1.92)$ & $0.1-10.0$ & $2.47(2.02)$ & $0.2-10.0$ \\
\hline Total usage time (hours/day) & $\mathrm{N} / \mathrm{A}^{\mathrm{a}}$ & $2.43(3.26)$ & $0-16$ & $2.26(3.25)$ & $0-16$ & $2.64(3.28)$ & $0-14$ \\
\hline Number of devices & N/A & $1.24(0.73)$ & $0-4$ & $1.15(0.71)$ & $0-4$ & $1.35(0.74)$ & $0-4$ \\
\hline Number of barriers & N/A & $1.47(1.20)$ & $0-6$ & $1.59(1.25)$ & $0-6$ & $1.32(1.13)$ & $0-5$ \\
\hline Need for cognitive closure & N/A & $3.56(0.56)$ & $1.80-5.00$ & $3.60(0.54)$ & $2.13-4.80$ & $3.51(0.59)$ & $1.80-5.00$ \\
\hline eHealth $^{\mathrm{b}}$ readiness & N/A & $15.56(7.55)$ & $6-33$ & $15.03(7.49)$ & $6-33$ & $16.21(7.60)$ & $6-32$ \\
\hline eHealth readiness close persons & N/A & $22.76(7.28)$ & $6-36$ & $23.07(7.07)$ & $6-36$ & $22.38(7.55)$ & $6-35$ \\
\hline
\end{tabular}

${ }^{\mathrm{a}} \mathrm{N} / \mathrm{A}$ : not applicable.

beHealth: electronic health.

\section{Predicting Information and Communication Technology Use and eHealth Readiness}

The evaluated structural model with standardized estimates of the regression paths is depicted in Figure 1. The model fit was good, $\chi_{438}^{2}=804.1$; the $\chi^{2}$ to degree of freedom ratio was 1.84 ; $\mathrm{CFI}=0.911 ; \mathrm{TLI}=0.899 ; \mathrm{SRMR}=0.064 ; \mathrm{RMSEA}=0.060 ; 95 \%$ CI (0.053-0.066), considering the complexity of the model, the sample size, and the initial fit of individual latent variables.

Estimates for the direct effects are displayed in Table 3. The results showed that the older an adult, the more barriers to using technology he/she perceived $(\beta=.15 ; P=.008)$ and the lower his/her ICT use $(\beta=-.34 ; P<.001)$ and eHealth readiness were $(\beta=-.21 ; P<.001)$. Individuals with a high NFCC also perceived more barriers $(\beta=.23 ; P=.01)$. Older adults who reported more barriers in fact used ICT less $(\beta=-.21 ; P=.001)$. The relationship between ICT use and eHealth readiness of older adults was positive, meaning that individuals who use ICT more are also more prepared and willing to accept eHealth technology $(\beta=.65$; $P<.001)$. None of the other direct effects were significant.

Indirect effect of NFCC on ICT use through perceived barriers was negative and significant $(\beta=-.049 ; P=.04)$, meaning that a higher NFCC was related to more perceived barriers. Indirect effect of NFCC on eHealth readiness of older adults through perceived barriers and ICT use was negative and significant as well $(\beta=-.031 ; P=.04)$. The expected direct effects of eHealth readiness of close persons on ICT use and eHealth readiness of older adults were not significant, but the total effect of eHealth readiness of close persons on eHealth readiness of older adults was positive and significant $(\beta=.18 ; P=.02)$.

The evaluated model explained $63.7 \%$ of the variance of older adults' eHealth readiness, $21.2 \%$ of variance of ICT use, and $8.5 \%$ of variance of the number of perceived barriers. 
Table 3. Estimates of direct effects.

\begin{tabular}{|c|c|c|c|c|c|}
\hline Regression path & Estimate $\mathrm{B}^{\mathrm{a}}$ & SE & $P$ value & $95 \% \mathrm{CI}$ & Standardized estimate $\beta$ \\
\hline $\mathrm{NFCC}^{\mathrm{b}} \rightarrow$ eHealth $^{\mathrm{c}}$ Readiness & -0.187 & 0.117 & .11 & -0.415 to 0.042 & -.091 \\
\hline NFCC $\rightarrow$ Barriers & 0.750 & 0.301 & .01 & 0.160 to 1.339 & .232 \\
\hline $\mathrm{NFCC} \rightarrow \mathrm{ICT}^{\mathrm{d}}$ use & -0.055 & 0.574 & .92 & -1.180 to 1.070 & -.008 \\
\hline Barriers $->$ eHealth Readiness & -0.034 & 0.028 & .23 & -0.090 to 0.022 & -.053 \\
\hline Barriers $\rightarrow$ ICT use & -0.429 & 0.133 & .001 & 0.689 to -0.169 & -.210 \\
\hline ICT use $\rightarrow>$ eHealth Readiness & 0.201 & 0.034 & $<.001$ & 0.134 to 0.268 & 647 \\
\hline eHealth Readiness Close Persons -> eHealth Readiness & 0.118 & 0.075 & .12 & -0.028 to 0.264 & .080 \\
\hline eHealth Readiness Close Persons $\rightarrow$ ICT use & 0.730 & 0.432 & .09 & -0.117 to 1.577 & .154 \\
\hline Age $\rightarrow$ eHealth Readiness & -0.017 & 0.004 & $<.001$ & -0.025 to -0.008 & -.207 \\
\hline Age $\rightarrow$ Barriers & 0.019 & 0.007 & .008 & 0.005 to 0.034 & .151 \\
\hline Age $\rightarrow$ ICT use & -0.089 & 0.017 & $<.001$ & -0.122 to -0.056 & -.342 \\
\hline Age $\rightarrow$ NFCC & 0.005 & 0.004 & .24 & -0.003 to 0.012 & .117 \\
\hline
\end{tabular}

${ }^{a}$ Nonstandardized estimate of direct effects (as compared with the standardized estimate $\beta$ ).

${ }^{\mathrm{b}} \mathrm{NFCC}$ : need for cognitive closure.

ceHealth: electronic health.

${ }^{\mathrm{d}}$ ICT: information and communication technology.

\section{Discussion}

\section{Principal Findings}

This study evaluated the predictors of ICT use and readiness to use eHealth technology by older adults. The study considered the role of perceived barriers, the role of close persons' eHealth readiness, and it was the first study to evaluate the influence of NFCC on ICT use and eHealth readiness of older adults. Although unable to definitively establish the direction of the studied relationships because of the cross-sectional nature of the data, the SEM analysis showed that apart from age, eHealth readiness was predicted by ICT use. Older adults who used ICT more in general were more ready to use technology for supporting health and healthy behaviors. Nevertheless, a reverse (higher eHealth readiness predicts more ICT use) or bidirectional relationship could also exist, but these were not specified and tested in the current model. Although the NFCC did not directly impact ICT use or eHealth readiness, NFCC exerted influence on ICT use and eHealth readiness indirectly through the number of perceived barriers. Individuals high in NFCC perceived more barriers to ICT. The number of barriers was, in turn, negatively related to their overall ICT use. Interestingly, there was evidence that significant others might influence older adults' eHealth readiness, although the mechanisms remain unclear (the direct effect of close persons' eHealth readiness on ICT use and eHealth readiness of older adults was not significant, but the total effect of close persons' eHealth readiness on the older adults' eHealth readiness was significant).

This study supported previous research [16-19] by finding that age plays an important role in ICT use and adoption. Older adults used ICT devices less, were less prepared to use it for monitoring and improving health, and perceived more barriers to ICT use than their younger counterparts. Similarly, in line with previous research [17-20], ICT usage was related to the level of education. Differences were found especially between older adults with primary education who used ICT to a lesser degree and perceived more barriers than college-educated older adults.

A novel predictor yielding interesting results was the NFCC. This research built upon the pioneering studies by Chernikova et al [35], which found NFCC to be related to intentions to use technological innovations and support the notion that NFCC may in fact play a role in technology adoption and use. The indirect effect of NFCC on ICT use and eHealth readiness through the number of perceived barriers (and in case of eHealth readiness through ICT use as well) suggests that individuals high in NFCC may perceive more barriers to ICT adoption and use, resulting in lower ICT use and eHealth readiness, but as a function of their reluctance to change and preference for tradition and security rather than the actual inability to use or learn to use ICT [34,51]. This notion should be evaluated in future research and should include a measure of perceived barriers by older adults as well as, for instance, a close person's evaluation of the older adult's actual barriers to technology adoption and use. Interestingly, NFCC indirectly predicted ICT use and eHealth readiness even when the effects of age were accounted for in the model, suggesting that this dispositional characteristic may, in part, help explain some of the age-related decline observed in ICT use.

The obtained results on the role of NFCC and perceived barriers on ICT use and readiness suggest interesting actionable implications. Researchers carrying out ICT use promoting interventions and programs might want to measure the level of NFCC of the participants in their programs. NFCC may then serve as a potential tailoring variable in the design of programs promoting ICT use, wherein depending on the individual's level 
of NFCC, intervention components explicitly focusing on reducing the number of perceived barriers could be incorporated into the intervention. The respective strategies to mitigate barriers would depend on the specific barriers but could range from providing training with ICT devices to financial support to presenting older adults with available technology and how it can enhance one's life. Effectively reducing perceived barriers (especially in high NFCC individuals) may then positively impact ICT acceptance and use. Moreover, NFCC has also been shown to be a situationally evocable state. This research suggests that when presenting a new ICT or eHealth device, application, or intervention to its potential users, it may be beneficial to lower their NFCC before and during the description of the device or intervention. This could be done, for example, by providing potential users with sufficient time when making decisions, by stressing the importance of forming an accurate judgment, or by aiding in the process of finding additional information on the matter before forming a judgement $[33,52]$. Experimental research testing these propositions is needed.

As for the role of significant others on older adults' adoption and use of technology, which has been proposed by several theoretical approaches $[17,53]$, the results are inconclusive at this point, and further research is needed to clarify this relationship. On the basis of these results, close persons might influence older adults' eHealth readiness, but the mechanisms are not clear. The amount, level, and specifics of support of close persons to older adults regarding ICT and specifically eHealth technologies were not explicitly assessed in the present research. Further research could focus on evaluating the specific mechanisms of close persons' influence on older adults' ICT acceptance and use. A better understanding of the role that close persons play in the adoption of ICT technologies by older adults would be particularly useful when designing ICT use promotion interventions for older adults. Close persons could help facilitate ICT adoption by the provision of specific types of support or through other mechanisms yet to be identified.

\section{Limitations and Further Research}

Considering the limited amount of research that has been conducted specifically on the relationship between NFCC and technology, this study should be regarded as an exploratory study, and the model should be confirmed and cross-validated on other samples to increase the validity of the results. A limitation of the present research is also the correlational nature of data, which does not allow for firm conclusions about the causality and direction of the relationships. Although the proposed relationships were theoretically construed and the proposed direction of causality seems theoretically plausible, further research should validate the findings in different older adult samples.

The sample size was rather low, considering the complexity of the evaluated models. It is also possible that an equally well-fitting structural model would result from a specification of different relationships. This further underscores the need for cross-validation and empirical testing of competing models in independent samples of older adults. Ideally, this research should involve studies with prospective, longitudinal, or experimental designs to allow for more definitive conclusions regarding the causality and time ordering of relationships under study.

Finally, little research has been conducted on the topic of ICT acceptance and use by Czech older adults - to our knowledge, we present the first systematic examination of ICT use and eHealth readiness in Czech older adults. Considering the rather low ICT usage and eHealth readiness in the current sample, it would be interesting to repeat the survey in a few years' time to evaluate the changes. Similarly, comparing specific subsamples of the older adult population such as older adults who are physically active, older adults visiting university classes, and people living in homes for the elderly could yield information about further factors influencing ICT acceptance and use, helping shape ICT use promotion efforts and policies related to ICT adoption across the population spectrum of older adults.

\section{Conclusions}

This is the first study to systematically evaluate Czech older adults' readiness to use technology for improving health, their related ICT use, and possible predictors, including NFCC and the role of significant others. Our results provide new insights into the predictors of older adults' readiness to use eHealth technology, especially with respect to NFCC. eHealth readiness was found to be affected directly by age and actual ICT use and indirectly by the NFCC and the number of perceived barriers toward using technology. These results are directly applicable for researchers or organizations carrying out interventions promoting the use of eHealth devices and applications.

Future researchers are encouraged to validate the findings in various older adult samples and further clarify the role of older adults' close persons. Additional studies, including prospective or experimental studies, are required to support the presented findings.

\section{Acknowledgments}

These results are part of the project that has received funding from the EU's Horizon 2020 research and innovation program under the Marie Skłodowska-Curie, and it is cofinanced by the South Moravian Region under grant agreement No. 665860. This material reflects only the author's attitudes, and the EU is not responsible for any possible use of the information contained in such material.

\section{Conflicts of Interest}

None declared.

\section{References}

1. United Nations. World Population Ageing 2007. New York: United Nations; 2007. 
2. United Nations. World Population Prospects: 2015 Revision. New York: United Nations; 2015.

3. Český statistický úřrad | ČSÚ.: Cesky statisticky urad; 2017. Use of ICT in Households and Individuals - 2017. Article in Czech. Využívání informačních a komunikačních technologií v domácnostech a mezi jednotlivci - 2017 URL: https://www. czso.cz/csu/czso/vyuzivani-informacnich-a-komunikacnich-technologii-v-domacnostech-a-mezi-jednotlivci-2017 [accessed 2020-03-23] [WebCite Cache ID 78CNVtyXV]

4. Anderson M, Perrin A. Pew Research Center. Washington, DC: Pew Research Center; 2017 May 17. Tech Adoption Climbs Among Older Adults URL: https://www.pewresearch.org/internet/2017/05/17/tech-adoption-climbs-among-older-adults/ [accessed 2020-03-23]

5. European Commission. Brussels: European Commission; 2010 Mar 3. Communication from the Commission. Europe 2020: A Strategy for Smart, Sustainable and Inclusive Growth URL: https://ec.europa.eu/eu2020/pdf/ COMPLET\%20EN\%20BARROSO\%20\%20\%20007\%20-\%20Europe\%202020\%20-\%20EN\%20version.pdf [accessed 2020-03-23]

6. Chesley N, Johnson BE. Information and communication technology use and social connectedness over the life course. Soc Compass 2014 Jun 19;8(6):589-602. [doi: 10.1111/soc4.12170]

7. Damodaran L, Gilbertson T, Olphert W, Sandhu J. Digital inclusion - the vision, the challenges and the way forward. Int J Adv Internet Technol 2015;8(3-4):78-92 [FREE Full text]

8. Backonja U, Hall AK, Thielke S. Older adults' current and potential uses of information technologies in a changing world: a theoretical perspective. Int J Aging Hum Dev 2014 Dec;80(1):41-63 [FREE Full text] [doi: 10.1177/0091415015591109] [Medline: 26215298]

9. Independent Age. Older People, Technology and Community: The Potential of Technology to Help Older People Renew or Develop Social Contacts and to Actively Engage in Their Communities. London: Independent Age; 2010.

10. Czaja SJ, Boot WR, Charness N, Rogers WA, Sharit J. Improving social support for older adults through technology: findings from the prism randomized controlled trial. Gerontologist 2018 May 8;58(3):467-477 [FREE Full text] [doi: 10.1093/geront/gnw249] [Medline: 28201730]

11. World Health Organization. 2016. International Classification of Health Interventions (ICHI) URL: https://www.who.int/ classifications/ichi/en/ [accessed 2020-03-23] [WebCite Cache ID 78CPF0d9q]

12. Muellmann S, Forberger S, Möllers T, Bröring E, Zeeb H, Pischke CR. Effectiveness of eHealth interventions for the promotion of physical activity in older adults: A systematic review. Prev Med 2018 Mar;108:93-110. [doi: 10.1016/j.ypmed.2017.12.026] [Medline: 29289643]

13. Elavsky S, Knapova L, Klocek A, Smahel D. Mobile health interventions for physical activity, sedentary behavior, and sleep in adults aged 50 years and older: a systematic literature review. J Aging Phys Act 2019 Aug 1;27(4):565-593. [doi: 10.1123/japa.2017-0410] [Medline: 30507266]

14. van Gemert-Pijnen JE, Nijland N, van Limburg M, Ossebaard HC, Kelders SM, Eysenbach G, et al. A holistic framework to improve the uptake and impact of eHealth technologies. J Med Internet Res 2011 Dec 5;13(4):e111 [FREE Full text] [doi: 10.2196/jmir.1672] [Medline: 22155738]

15. Mattila E, Orsama A, Ahtinen A, Hopsu L, Leino T, Korhonen I. Personal health technologies in employee health promotion: usage activity, usefulness, and health-related outcomes in a 1-year randomized controlled trial. JMIR Mhealth Uhealth 2013 Jul 29;1(2):e16 [FREE Full text] [doi: 10.2196/mhealth.2557] [Medline: 25098385]

16. Magsamen-Conrad K, Upadhyaya S, Joa CY, Dowd J. Bridging the Divide: Using UTAUT to predict multigenerational tablet adoption practices. Comput Human Behav 2015 Sep 1;50:186-196 [FREE Full text] [doi: 10.1016/j.chb.2015.03.032] [Medline: 25937699]

17. Vroman KG, Arthanat S, Lysack C. 'Who over 65 is online?' Older adults' dispositions toward information communication technology. Comp Hum Behav 2015 Feb;43:156-166. [doi: 10.1016/j.chb.2014.10.018]

18. Wagner N, Hassanein K, Head M. Computer use by older adults: a multi-disciplinary review. Comput Hum Behav 2010 Sep;26(5):870-882. [doi: 10.1016/j.chb.2010.03.029]

19. Olson KE, O'Brien MA, Rogers WA, Charness N. Diffusion of technology: frequency of use for younger and older adults. Ageing Int 2011 Mar;36(1):123-145 [FREE Full text] [doi: 10.1007/s12126-010-9077-9] [Medline: 22685360]

20. Selwyn N, Gorard S, Furlong J, Madden L. Older adults' use of information and communications technology in everyday life. Ageing Soc 2003 Sep 2;23(5):561-582. [doi: 10.1017/S0144686X03001302]

21. Vorrink SN, Antonietti AM, Kort HS, Troosters T, Zanen P, Lammers JJ. Technology use by older adults in the Netherlands and its associations with demographics and health outcomes. Assist Technol 2017;29(4):188-196. [doi:

10.1080/10400435.2016.1219885] [Medline: 27548101]

22. Davis FD. Perceived usefulness, perceived ease of use, and user acceptance of information technology. Manag Inf Syst Q 1989 Sep;13(3):319-340. [doi: 10.2307/249008]

23. Macedo IM. Predicting the acceptance and use of information and communication technology by older adults: an empirical examination of the revised UTAUT2. Comput Hum Behav 2017 Oct;75:935-948. [doi: 10.1016/j.chb.2017.06.013]

24. Marangunić N, Granić A. Technology acceptance model: a literature review from 1986 to 2013. Univ Access Inf Soc 2015;14(1):81-95. [doi: 10.1007/s10209-014-0348-1] 
25. Taylor S, Todd P. Decomposition and crossover effects in the theory of planned behavior: A study of consumer adoption intentions. Int J Res Mark 1995 Jul;12(2):137-155. [doi: 10.1016/0167-8116(94)00019-K]

26. Venkatesh V, Morris MG, Davis GB, Davis FD. User acceptance of information technology: toward a unified view. Manag Inf Syst Q 2003;27(3):425-478. [doi: 10.2307/30036540]

27. Czaja SJ, Charness N, Fisk AD, Hertzog C, Nair SN, Rogers WA, et al. Factors predicting the use of technology: findings from the Center for Research and Education on Aging and Technology Enhancement (CREATE). Psychol Aging 2006 Jun;21(2):333-352 [FREE Full text] [doi: 10.1037/0882-7974.21.2.333] [Medline: 16768579]

28. Mitzner T, Savla J, Boot W, Sharit J, Charness N, Czaja S, et al. Technology adoption by older adults: findings from the PRISM Trial. Gerontologist 2019 Jan 9;59(1):34-44 [FREE Full text] [doi: 10.1093/geront/gny113] [Medline: 30265294]

29. Eastman JK, Iyer R. The elderly's uses and attitudes towards the internet. J Consum Mark 2004 May;21(3):208-220. [doi: 10.1108/07363760410534759]

30. Chopik WJ, Rikard R, Cotten SR. Individual difference predictors of ICT use in older adulthood: A study of 17 candidate characteristics. Comput Hum Behav 2017 Nov;76:526-533. [doi: 10.1016/j.chb.2017.08.014]

31. Cacioppo JT, Petty RE. The need for cognition. J Pers Soc Psychol 1982 Jan;42(1):116-131. [doi: 10.1037/0022-3514.42.1.116]

32. Webster DM, Kruglanski AW. Individual differences in need for cognitive closure. J Pers Soc Psychol 1994;67(6):1049-1062. [doi: 10.1037/0022-3514.67.6.1049]

33. Roets A, Kruglanski A, Kossowska M, Pierro A, Hong Y. The motivated gatekeeper of our minds: new directions in need for closure theory and research. Adv Exp Soc Psychol 2015;52:221-283. [doi: 10.1016/bs.aesp.2015.01.001]

34. Kruglanski AW, Pierro A, Higgins ET, Capozza D. 'On the move' or 'Staying put': locomotion, need for closure, and reactions to organizational change. J Appl Soc Pyschol 2007 Jun;37(6):1305-1340. [doi: 10.1111/j.1559-1816.2007.00214.x]

35. Chernikova M, Kruglanski A, Giovannini D, Vezzali L, Su J. Need for closure and reactions to innovation. J Appl Soc Psychol 2017 Jun 23;47(9):473-481. [doi: 10.1111/jasp.12451]

36. Pan S, Jordan-Marsh M. Internet use intention and adoption among Chinese older adults: from the expanded technology acceptance model perspective. Comput Hum Behav 2010 Sep;26(5):1111-1119. [doi: 10.1016/j.chb.2010.03.015]

37. Ryu M, Kim S, Lee E. Understanding the factors affecting online elderly user's participation in video UCC services. Comput Hum Behav 2009 May;25(3):619-632. [doi: 10.1016/j.chb.2008.08.013]

38. Fausset C, Harley L, Farmer S, Fain B. Older Adults' Perceptions and Use of Technology: A Novel Approach. In: Proceedings of the International Conference on Universal Access in Human-Computer Interaction. Proceedings of the 7th International Conference Universal Access in Human-Computer Interaction: User and Context Diversity; 2013 Presented at: UAHCI'13; 21-26 July 2013; Las Vegas p. 51-58. [doi: 10.1007/978-3-642-39191-0_6]

39. Kopecky K, Szotkowski R, Kozisek M, Kasackova J. Projekt E-bezpečí. 2018. Old Men on the Net (Research Report). Article in Croatian. Starci na netu (výzkumná zpráva) URL: https://www.e-bezpeci.cz/index.php/ke-stazeni/vyzkumne-zpravy/ 102-starci-na-netu-2017-2018/file [accessed 2020-03-23] [WebCite Cache ID 78CWLKXp7]

40. Bhalla A, Durham RL, Al-Tabaa N, Yeager C. The development and initial psychometric validation of the eHealth readiness scale. Comput Hum Behav 2016 Dec;65:460-467. [doi: 10.1016/j.chb.2016.09.015]

41. Maneesriwongul W, Dixon JK. Instrument translation process: a methods review. J Adv Nurs 2004 Oct;48(2):175-186. [doi: 10.1111/j.1365-2648.2004.03185.x] [Medline: 15369498]

42. Roets A, van Hiel A. Item selection and validation of a brief, 15 -item version of the Need for Closure Scale. Pers Individ Dif 2011 Jan;50(1):90-94. [doi: 10.1016/j.paid.2010.09.004]

43. Sirucek J, Tapal A, Linhartova P. The need for cognition: A study of the psychometric characteristics of the abbreviated Czech version The Scale of the Need for Cognition. Article in Czech. Potřeba poznávání: Studie psychometrických charakteristik zkrácené české verze Škály potřeby poznávání. Czechoslovak Psychol 2014;58(1):52-61 [FREE Full text]

44. R Core Team. The R Project for Statistical Computing. Vienna: R Foundation for Statistical Computing; 2017. URL: https:/ /www.r-project.org/ [accessed 2020-03-23]

45. Bollen KA. Structural Equations With Latent Variables. New York: Wiley; 1989.

46. Hu L, Bentler PM. Cutoff criteria for fit indexes in covariance structure analysis: Conventional criteria versus new alternatives. Struct Equ Modeling 1999 Jan;6(1):1-55. [doi: 10.1080/10705519909540118]

47. Browne MW, Cudeck R. Alternative ways of assessing model fit. In: Bollen KA, Long JS, editors. Testing Structural Equation Models. Newbury Park: Sage; 1993:136-162.

48. MacCallum RC, Browne MW, Sugawara HM. Power analysis and determination of sample size for covariance structure modeling. Psychol Methods 1996;1(2):130-149. [doi: 10.1037/1082-989X.1.2.130]

49. Marsh HW, Hau K, Wen Z. In search of golden rules: comment on hypothesis-testing approaches to setting cutoff values for fit indexes and dangers in overgeneralizing Hu and Bentler's (1999) findings. Struct Equ Modeling 2004 Jul;11(3):320-341. [doi: 10.1207/s15328007sem1103_2]

50. Bentler PM, Bonett DG. Significance tests and goodness of fit in the analysis of covariance structures. Psychol Bull 1980;88(3):588-606. [doi: 10.1037/0033-2909.88.3.588]

51. Calogero RM, Bardi A, Sutton RM. A need basis for values: associations between the need for cognitive closure and value priorities. Pers Individ Dif 2009 Jan;46(2):154-159. [doi: 10.1016/j.paid.2008.09.019] 
52. Kruglanski AW, Webster DM. Motivated closing of the mind: 'seizing' and 'freezing'. Psychol Rev 1996 Apr;103(2):263-283. [doi: 10.1037/0033-295x.103.2.263] [Medline: 8637961]

53. Bronfenbrenner U. The Ecology Of Human Development: Experiments By Nature And Design. Cambridge: Harvard University Press; 1979.

\section{Abbreviations}

CFI: comparative fit index

eHealth: electronic health

EU: European Union

ICT: information and communication technology

mHealth: mobile health

NFCC: need for cognitive closure

RMSEA: root mean square error of approximation

SEM: structural equation modeling

SRMR: standardized root mean square residual

TLI: Tucker-Lewis Index

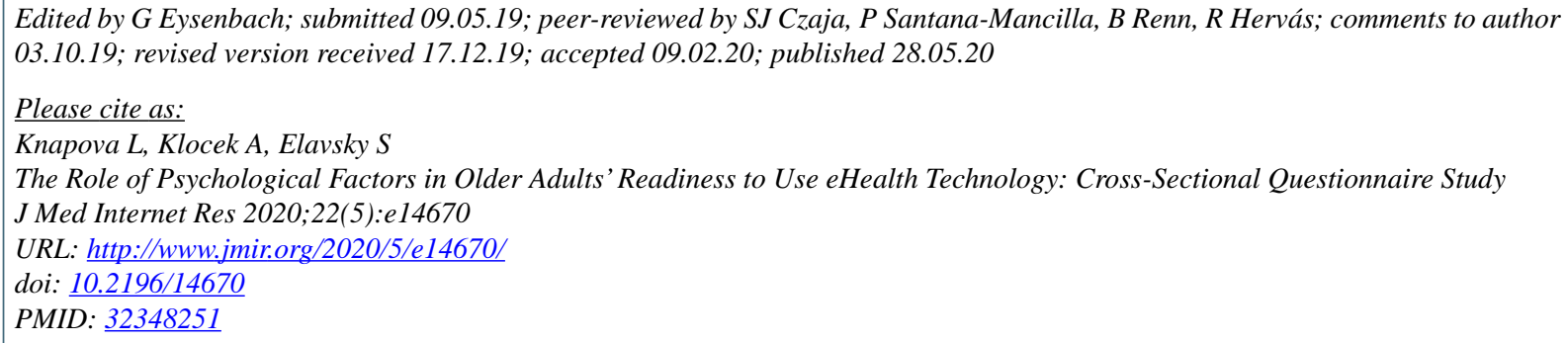

CLenka Knapova, Adam Klocek, Steriani Elavsky. Originally published in the Journal of Medical Internet Research (http://www.jmir.org), 28.05.2020. This is an open-access article distributed under the terms of the Creative Commons Attribution License (https://creativecommons.org/licenses/by/4.0/), which permits unrestricted use, distribution, and reproduction in any medium, provided the original work, first published in the Journal of Medical Internet Research, is properly cited. The complete bibliographic information, a link to the original publication on http://www.jmir.org/, as well as this copyright and license information must be included. 